\title{
A 6-week, multicentre, randomised, double-blind, double-dummy, active-controlled, clinical safety study of lumiracoxib and rofecoxib in osteoarthritis patients
}

\author{
Kirstin Stricker ${ }^{1}$, Sue $\mathrm{Yu}^{2}$ and Gerhard Krammer*1
}

\begin{abstract}
Address: ${ }^{1}$ Novartis Pharma AG Postfach, CH-4002, Basel, Switzerland and ${ }^{2}$ Novartis Pharmaceuticals Corporation, One health Plaza East, Hanover, NJ, 07936-1080, USA

Email: Kirstin Stricker - kirstin.stricker@novartis.com; Sue Yu - sue.yu@novartis.com; Gerhard Krammer* - gerhard.krammer@novartis.com

* Corresponding author
\end{abstract}

Published: 8 September 2008

BMC Musculoskeletal Disorders 2008, 9:1 18 doi:10.1 186/147I-2474-9-1/8

Received: 19 February 2008

Accepted: 8 September 2008

This article is available from: http://www.biomedcentral.com/147I-2474/9/I I8

(c) 2008 Stricker et al; licensee BioMed Central Ltd.

This is an Open Access article distributed under the terms of the Creative Commons Attribution License (http://creativecommons.org/licenses/by/2.0), which permits unrestricted use, distribution, and reproduction in any medium, provided the original work is properly cited.

\begin{abstract}
Background: Lumiracoxib is a selective cyclooxygenase-2 inhibitor effective in the treatment of osteoarthritis $(\mathrm{OA})$ with a superior gastrointestinal $(\mathrm{Gl})$ safety profile as compared to traditional nonsteroidal anti-inflammatory drugs (NSAIDs, ibuprofen and naproxen). This safety study compared the GI tolerability, the blood pressure (BP) profile and the incidence of oedema with lumiracoxib and rofecoxib in the treatment of OA. Rofecoxib was withdrawn worldwide due to an associated increased risk of CV events and lumiracoxib has been withdrawn from Australia, Canada, Europe and a few other countries following reports of suspected adverse liver reactions.

Methods: This randomised, double-blind study enrolled 309 patients (aged greater than or equal to 50 years) with primary $O A$ across $5 \mathrm{I}$ centres in Europe. Patients were randomly allocated to receive either lumiracoxib $400 \mathrm{mg}$ od (four times the recommended dose in OA) $(n=154)$ or rofecoxib $25 \mathrm{mg}$ od $(n=$ 155). The study was conducted for 6 weeks and assessments were performed at Weeks 3 and 6 . The primary safety measures were the incidence of predefined Gl adverse events (AEs) and peripheral oedema. The secondary safety measures included effect of treatment on the mean sitting systolic and diastolic blood pressure (msSBP and msDBP). Tolerability of lumiracoxib $400 \mathrm{mg}$ was assessed by the incidence of AEs.

Results: Lumiracoxib and rofecoxib displayed similar Gl safety profiles with no statistically significant difference in predefined GI AEs between the two groups ( $43.5 \%$ vs. $37.4 \%$, respectively). The incidence and severity of individual predefined GI AEs was comparable between the two groups. The incidence of peripheral oedema was low and identical in both the groups $(n=9,5.8 \%)$. Only one patient in the lumiracoxib group and three patients in the rofecoxib group had a moderate or severe event. At Week 6 there was a significantly lower msSBP and msDBP in the lumiracoxib group compared to the rofecoxib group $(p<0.05)$. A similar percentage of patients in both groups showed an improvement in target joint pain and disease activity. The tolerability profile was similar in both the treatment groups.

Conclusion: Lumiracoxib $400 \mathrm{mg}$ od (four times the recommended dose in OA) provided a comparable $\mathrm{Gl}$ safety profile to rofecoxib $25 \mathrm{mg}$ od (therapeutic dose). However, lumiracoxib was associated with a significantly better BP profile as compared to rofecoxib.
\end{abstract}

Trial registration number -: NCT00637949 


\section{Background}

Osteoarthritis (OA) is a common condition that affects $18 \%$ women and $10 \%$ men (aged > 60 years) worldwide [1]. Treatment for these patients is aimed at controlling pain, improving functional abilities and enhancing health-related quality-of-life [2].

Non-selective non-steroidal anti-inflammatory drugs (NSAIDs) such as naproxen and ibuprofen are widely used for pain relief in OA. However, upper gastrointestinal (GI) symptoms such as dyspepsia and more importantly ulcer complications occur in $15-60 \%$ of NSAID users and frequently necessitate co-therapy with $\mathrm{H}_{2}$ receptor antagonists or proton pump inhibitors [3-6]. In a prospective cohort study, it was observed that $81 \%$ of patients taking NSAIDs and having serious GI complications had no prior GI symptoms [7] and in a survey in the US among NSAID users, it was observed that nearly $75 \%$ of those who regularly used NSAIDs did not know about or were unconcerned about NSAID related GI complications [8]. GI adverse events (AEs) are the main factors limiting the use of NSAIDs and represent a significant health burden [6]. Renal impairment, vascular constriction and GI AEs are attributed to inhibition of cyclooxygenase-1 (COX-1), anti-inflammatory and analgesic effect is attributed to inhibition of COX-2. Hence, selective COX-2 inhibitors like celecoxib and rofecoxib provide a more favourable GI safety profile with similar efficacy as compared to non-selective NSAIDs in patients with OA $[9,10]$. Rofecoxib, however, was withdrawn worldwide on September 30, 2004 due to an increase in the cardiovascular (CV) risk [11]. Following this withdrawal, concerns have also been raised regarding $\mathrm{CV}$ safety of both selective COX-2 inhibitors and traditional NSAIDs. These concerns arose initially for selective COX-2 inhibitors following the worldwide withdrawal of rofecoxib. Meta-analyses have since reported an increased risk of $\mathrm{CV}$ events with both traditional NSAIDs and COX-2 inhibitors and both carry warnings to this effect in their prescribing information [12-14].

Lumiracoxib is a structurally distinct, selective COX-2 inhibitor for the management of $\mathrm{OA}$ and acute pain. Lumiracoxib is effective in treating acute pain conditions such as post-operative dental pain [15], acute gout [16], arthroplasty [17], sprains and strains [18] and in treating chronic pain associated with OA $[19,20]$.

The 52-week Therapeutic Arthritis Research and Gastrointestinal Event Trial (TARGET) in 18000 patients with OA investigated the GI, CV and overall safety profile of lumiracoxib $400 \mathrm{mg}$ od (four times the recommended dose for OA) compared to two traditional NSAIDs, naproxen 500 $\mathrm{mg}$ bid and ibuprofen $800 \mathrm{mg}$ tid $[21,22]$. The TARGET study showed that lumiracoxib was associated with a $79 \%$ decrease in upper GI complications compared to traditional NSAIDs (non-aspirin population) [21]. The GI benefit with lumiracoxib compared to traditional NSAIDs occurred within 8 days of treatment [23]. In TARGET lumiracoxib was also associated with an improved blood pressure (BP) profile as compared to the traditional NSAIDs, already after 4 weeks of treatment [24] and the effect was maintained until 52 weeks [22].

The present short-term safety study assessed the GI tolerability of a 6-week treatment with lumiracoxib $400 \mathrm{mg}$ od (four times the recommended dose for OA) as compared to rofecoxib $25 \mathrm{mg}$ od (therapeutic dose) in patients with OA. In addition, the study also assessed renal effects including the incidence of peripheral oedema and changes in BP in the two treatment groups.

\section{Methods \\ Study design}

This study was a 6-week, multicentre, randomised, double-blind, double-dummy, active-controlled, parallelgroup, safety study of lumiracoxib $400 \mathrm{mg}$ od (four times the recommended dose for OA) compared to rofecoxib 25 mg od. The study enrolled subjects with primary OA across 51 centres in Europe. This study was performed according to Good Clinical Practice guidelines. Ethics committee approval from all participating institutions was obtained in accordance with the Declaration of Helsinki and all patients gave their written informed consent before enrolment. The study had a 3-7 day wash-out period, 6-week treatment period and a follow-up by phone call 2 weeks after the end of study/early termination.

\section{Study population}

Symptomatic patients (aged $\geq 50$ years) with OA as defined by the American College of Rheumatology criteria were recruited. The criteria for inclusion were primary OA for at least 3 months in the hip, hand, knee or spine (cervical or lumbar) and pain in the target joint of at least moderate intensity (Likert scale). Patients also needed to be on NSAID or other analgesic therapy or expected to need NSAID treatment for at least 6 weeks.

The exclusion criteria were secondary OA and/or history/ evidence of significant diseases in the affected joints, evidence of active ulceration or bleeding of the upper GI tract, upper GI tract malignancies, diseases of the intestinal tract and bleeding diathesis. Patients were excluded if they had clinically significant hepatic or renal disease, evidence of hepatic, renal or blood coagulation disorders or anaemia, hypertension, type I diabetes or other significant medical problems, used systemic steroids, intra-articular hyaluronic acid injections, $\mathrm{H}_{2}$ receptor antagonists, proton pump inhibitors, sucralfate or prostaglandin ana- 
logues in the past month. Pregnant or lactating women and women not on acceptable form of contraception were also excluded.

\section{Study medication and assessments}

Patients were randomly allocated in the ratio of $1: 1$ to receive either lumiracoxib $400 \mathrm{mg}$ od (four times the recommended dose for OA) or rofecoxib $25 \mathrm{mg}$ od. Lumiracoxib (Prexige ${ }^{\circledast}$ Novartis Pharma AG, Basel, Switzerland) was provided as $2 \times 200 \mathrm{mg}$ tablets with matching placebos and rofecoxib as $25 \mathrm{mg}$ capsules with matching placebos. Patients were asked to take the medication once every morning at approximately the same time. Compliance with study drug was defined as patients taking $\geq 80 \%$ of the full daily dose. To control GI symptoms, patients were allowed a maximum of eight antacid tablets (calcium carbonate $680 \mathrm{mg} / \mathrm{magnesium}$ carbonate $80 \mathrm{mg}$ ) per day as rescue medication. Patients received the study medication for 6 weeks.

\section{Safety assessments}

The key primary assessment was incidence of at least one of the predefined GI AEs: abdominal pain, constipation, diarrhoea, nausea, vomiting, dyspepsia and dysphagia. The other primary assessment was incidence of peripheral oedema: lower limb oedema, upper limb oedema, peripheral swelling and peripheral oedema. The secondary safety assessments were incidence of moderate and severe predefined GI AEs, incidence of each individual predefined GI $\mathrm{AE}$, discontinuations from study because of any AE or GI $\mathrm{AE}$ and time to discontinuation, mean sitting systolic and diastolic blood pressure (msSBP and msDBP), and the number of tablets of antacid rescue medication taken. Study assessments were performed at baseline, Weeks 3 and 6 .

Tolerability was evaluated by recording AEs during the entire study period. A follow-up phone call 2 weeks after the end of study was carried out to evaluate serious adverse events (SAEs) after study drug discontinuation. Investigators were requested to report all SAE's which occurred within 4 weeks after last dose of study drug intake. Vital signs including BP measurements and standard laboratory tests were performed at baseline, Weeks 3 and 6. ECG recordings were performed at baseline and Week 6.

\section{Efficacy assessment}

Efficacy variables were overall pain intensity in the target joint and the global assessments of disease activity by patients and physicians on a 5-point Likert scale at Weeks 3 and 6. For overall pain intensity in the target joint, patients were classified as improved if endpoint assessment was "none" or improved by at least two grades from baseline on the Likert scale. For patient's and physician's global assessment of disease activity, patients were classified as improved if endpoint assessment was "very good" or improved by at least two grades from baseline.

\section{Statistical analysis}

The categorical efficacy variables were analysed in the intent-to-treat (ITT) population defined as all randomised patients who received study medication. A multiple logistic model (PROC LOGISTIC in SAS), which considered treatment as main effect was used for the analysis. The treatment contrasts were tested at a two-sided 5\% significance level and presented as odds ratios (ORs) together with their 95\% confidence intervals (CIs). Missing data for efficacy variables were imputed using the last-observation-carried-forward (LOCF) method. The primary safety endpoints were analysed in the safety population defined as all patients randomised to treatment, who had been exposed to study medication. A multiple logistic model, which took into account country and treatment as the main effect was used for the analysis. The treatment contrasts were tested at a two-sided 5\% level of significance and presented as ORs together with their 95\% CIs. If the estimated incidence rates were less than $5 \%$, or if the logistic regression model did not converge, Fisher's exact test was used for the comparisons. Analysis was repeated in the per-protocol (PP) population defined as a sub-population of the safety population for sensitivity reasons. Between-treatment comparisons for msSBP and msDBP were performed by means of analysis of covariance (ANCOVA). For the ANCOVA models, treatment and country were taken as fixed effects and the respective baseline values as covariate. Time to discontinuation from study due to any AE or GI AE was analysed using life-table methods. Patient compliance and other categorical safety endpoints were analysed using a multiple logistic model at a two-sided 5\% significance level and presented as ORs together with their $95 \%$ CIs.

\section{Sample size and power considerations}

The determination of the sample size was based on the key primary safety variable, the incidence of predefined GI AEs. A two-group continuity corrected chi-squared test with a two-sided $5 \%$ significance level had $80 \%$ power to detect a clinically relevant difference between the treatment groups, assuming $28 \%$ in the rofecoxib group and $14 \%$ in the lumiracoxib group when the sample size is 146 patients per treatment arm. Three hundred and four patients (152 each on lumiracoxib and rofecoxib) needed to be randomised to allow for a $4 \%$ dropout rate.

\section{Results}

After an initial wash-out period of 3-7 days, a total of 309 patients were randomised to either lumiracoxib $400 \mathrm{mg}$ od $(n=154)$ or rofecoxib $25 \mathrm{mg}$ od $(n=155)$ (Figure 1$)$. All randomised patients were included in the ITT and 
safety populations. At baseline, the treatment groups were comparable in terms of demographic and baseline characteristics (Table 1). Medical histories indicated that more patients on lumiracoxib had vascular disorders as compared to rofecoxib (54.5\% vs. $46.5 \%$, respectively). History of cardiac disorders at baseline was more frequent in lumiracoxib patients $(16 \%)$ than rofecoxib patients (11\%). In both the groups, a similar percentage (42\%) of patients had previously undergone surgical and medical procedures. More than $90 \%$ of patients in both the treatment groups completed the study. Major protocol violations resulting in exclusion from the PP population occurred in 13 patients receiving lumiracoxib and seven patients receiving rofecoxib.

\section{Primary safety endpoints}

There was no statistically significant difference in the overall incidence of key primary assessment variables (predefined GI AEs - abdominal pain, constipation, diarrhea, nausea, vomiting, dyspepsia and dysphagia) between the treatment groups (OR: $1.31 ; 95 \% \mathrm{CI}: 0.82,2.11, p=$ $0.258)$. Predefined GI AEs were reported in $43.5 \%(n=$ $67)$ of patients in lumiracoxib group and $37.4 \%(n=58)$ of patients in rofecoxib group. Thus, overall both the study drugs displayed similar GI safety profiles. The incidence of the other primary assessment variable, peripheral oedema was low in both the treatment groups $(n=9$, $5.8 \%$ ) (Figure 2).

\section{Secondary safety endpoints}

There was no statistically significant difference between lumiracoxib and rofecoxib for the incidence of individual predefined GI AEs. Minor differences between lumiracoxib and rofecoxib in the incidence rates for diarrhoea (11.0\% vs. 5.2\%), dyspepsia (26.6\% vs. 20.6\%) and constipation $(2.6 \%$ vs. $0.6 \%)$ were observed, but were not statistically significant. When the incidence rates of these predefined GI AEs were analysed based on their severity it was observed that moderate or severe predefined GI AEs associated with lumiracoxib and rofecoxib were comparable with the exception of dyspepsia that occurred more often in the lumiracoxib group (11.0\% lumiracoxib vs. $4.5 \%$ rofecoxib, $p=0.035$, Fisher's exact test [Table 2]).

The rate of moderate-to-severe peripheral oedema was low in both treatment groups. Only one patient in the lumiracoxib group $(0.6 \%)$ versus three patients $(1.9 \%)$ in the rofecoxib group had a moderate-to-severe event. This numerical difference was not statistically significant. After 6 weeks of treatment, a significantly lower msSBP and msDBP was observed with lumiracoxib as compared to rofecoxib (least square estimated difference: $-3.13 \mathrm{mmHg}$,

Table I: Demographic and baseline characteristics (safety population)

\begin{tabular}{|c|c|c|}
\hline & $\begin{array}{l}\text { Lumiracoxib } 400 \mathrm{mg} \text { od } \\
(n=154)\end{array}$ & $\begin{array}{c}\text { Rofecoxib } 25 \mathrm{mg} \text { od } \\
(n=155)\end{array}$ \\
\hline Age (years) ${ }^{\dagger}$ & $65.3 \pm 8.49$ & $65.5 \pm 8.67$ \\
\hline Women, $n(\%)$ & $94(61.0)$ & $100(64.5)$ \\
\hline $\mathrm{BMI}\left(\mathrm{kg} / \mathrm{m}^{2}\right)^{\dagger}$ & $29.1 \pm 5.21$ & $28.3 \pm 4.51$ \\
\hline \multicolumn{3}{|l|}{ Race } \\
\hline Caucasians, $n(\%)$ & $154(100.0)$ & $153(98.7)$ \\
\hline Other & $0(0.0)$ & $2(1.2)$ \\
\hline Disease duration (years) ${ }^{\dagger}$ & $7.41 \pm 7.058$ & $8.37 \pm 8.407$ \\
\hline \multicolumn{3}{|c|}{ Physician's global assessment of disease activity $n(\%)$} \\
\hline Very good & $\mathrm{I}(0.6)$ & $2(1.3)$ \\
\hline Good & $3(1.9)$ & $5(3.2)$ \\
\hline Fair & $75(48.7)$ & $66(42.6)$ \\
\hline Poor & $69(44.8)$ & $76(49.0)$ \\
\hline Very poor & $6(3.9)$ & $6(3.9)$ \\
\hline \multicolumn{3}{|c|}{ Patient's global assessment of disease activity $n(\%)$} \\
\hline Very good & $\mathrm{I}(0.6)$ & I (0.6) \\
\hline Good & $9(5.8)$ & $6(3.9)$ \\
\hline Fair & $51(33.1)$ & $57(36.8)$ \\
\hline Poor & $78(50.6)$ & 77 (49.7) \\
\hline Very poor & $15(9.7)$ & $14(9.0)$ \\
\hline \multicolumn{3}{|c|}{ Pain intensity assessment $n(\%)$} \\
\hline Moderate & $74(48.1)$ & 74 (47.7) \\
\hline Severe & $67(43.5)$ & $67(43.2)$ \\
\hline Extreme & $13(8.4)$ & $14(9.0)$ \\
\hline Current smokers, $n$ (\%) & $24(15.6)$ & $26(16.8)$ \\
\hline
\end{tabular}

$\mathrm{BMI}=$ body mass index; Other $=$ Black/African American and Asian or Pacific islander; SD $=$ standard deviation.

tMean \pm SD 


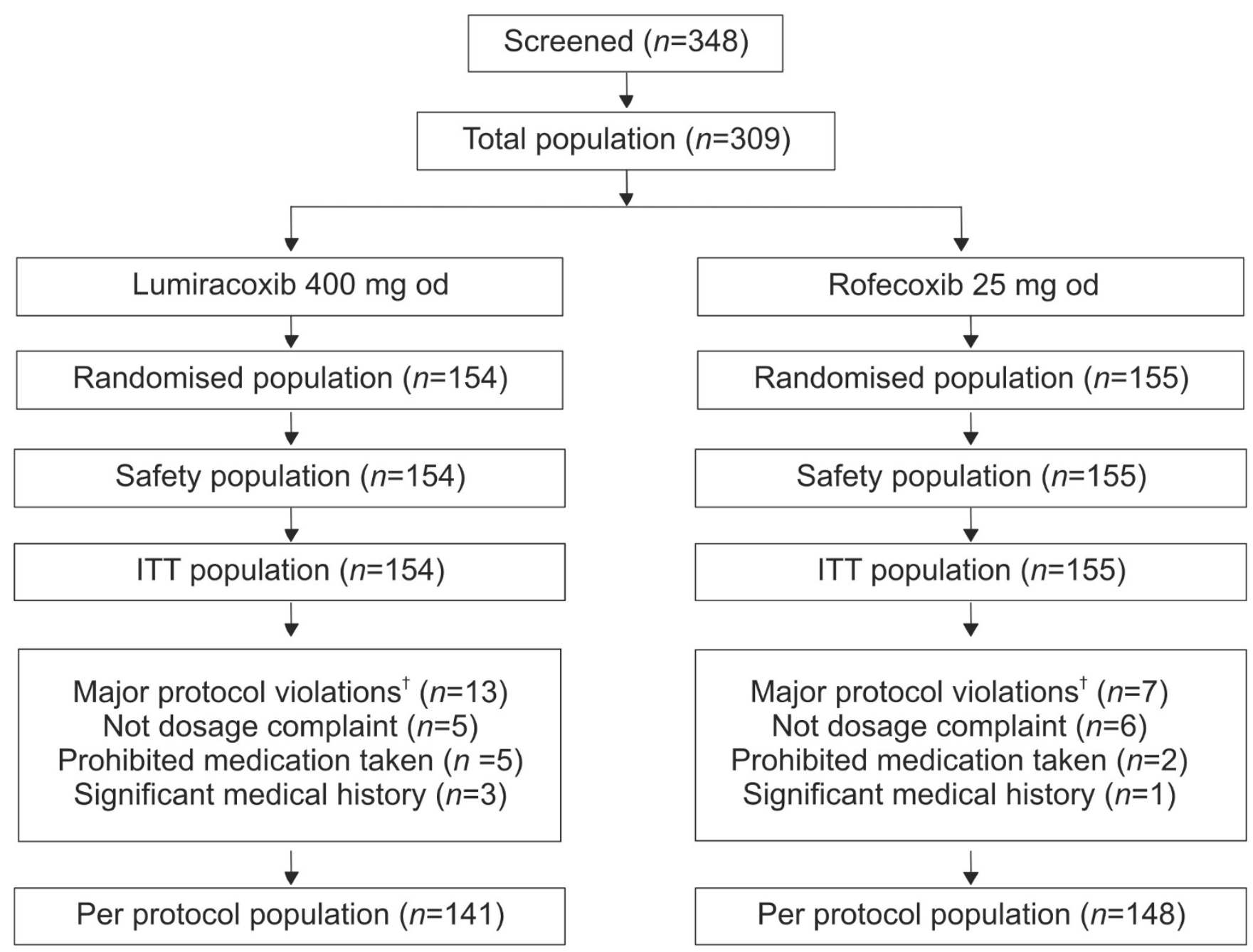

\section{Figure I}

Patient flow diagram. †Patients with multiple occurrences of a major protocol violation (PV) were counted only once in that category of PV.

95\% CI: $-6.17,-0.10, p=0.043$ for msSBP and -1.73 mmHg, 95\% CI: $-3.43,-0.03$, for msDBP, $p=0.046$ [Figure 3]). The mean number of antacid tablets taken was the same in both treatment groups (0.2 tablets/day).

The most frequently reported AEs (by preferred term) during this study are listed in Table 3. The incidence of AEs was comparable between lumiracoxib and rofecoxib. The most commonly reported AEs by primary system organ class were GI disorders, infections and infestations, and musculoskeletal and connective tissue disorders, which were similar in incidence in both treatment groups. Studydrug related AEs as suspected by the investigator were reported in $40.9 \%$ of patients in the lumiracoxib group and $37.4 \%$ of patients in the rofecoxib group. As expected in a study focussing on GI safety, AEs were most commonly reported in the GI system. Three rofecoxib-treated patients experienced AEs that led to temporary interruption of study medication (Table 4).

Discontinuations due to GI AEs occurred in $4.5 \%$ and $2.6 \%$ of the patients treated with lumiracoxib and rofecoxib, respectively $(p=0.359)$. The mean time to discontinuation for patients treated with lumiracoxib as compared to rofecoxib for any AE (23.3 days vs. 21.7 days, respectively) and for GI AEs (23.4 days vs. 25.3 days, respectively) was comparable. A similar proportion of patients discontinued from the study due to any AE in both groups $(5.2 \%$ of lumiracoxib and $4.5 \%$ of rofecoxib patients).

No drug-related SAEs or deaths were reported during the course of the study. One SAE (vaginal haemorrhage) was reported in the rofecoxib group. 


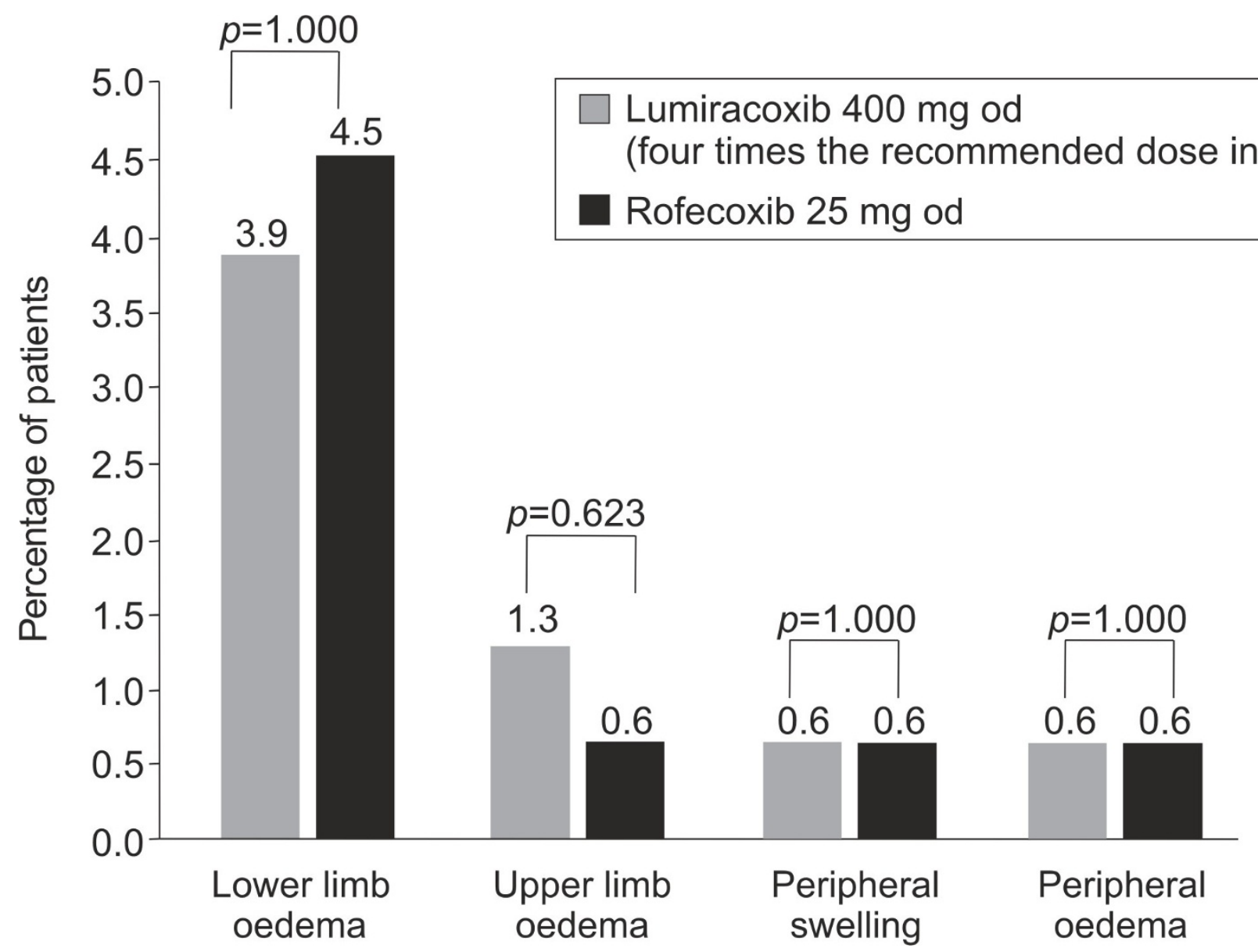

Figure 2

Incidence of peripheral oedema in patients treated with lumiracoxib and rofecoxib (safety population). The incidence of peripheral oedema at Week 6 . Pairwise comparisons tested at the two-sided $5 \%$ significance level. $p$-value computed using Fisher's exact test. OA, osteoarthritis.

Table 2: Incidence of moderate or severe predefined GI AEs (safety population)

\begin{tabular}{|c|c|c|}
\hline Predefined GI AEs & $\begin{array}{c}\text { Lumiracoxib } 400 \mathrm{mg} \text { od } \\
(n=154) \\
n(\%)\end{array}$ & $\begin{array}{c}\text { Rofecoxib } 25 \mathrm{mg} \text { od } \\
(n=155) \\
n(\%)\end{array}$ \\
\hline Abdominal pain & $6(3.9)$ & $6(3.9)$ \\
\hline Constipation & I (0.6) & I (0.6) \\
\hline Diarrhoea & $4(2.6)$ & $2(1.3)$ \\
\hline Dyspepsia* & $17(11.0)$ & $7(4.5)$ \\
\hline Dysphagia & $\mathrm{I}(0.6)$ & $0(0.0)$ \\
\hline Nausea & $3(1.9)$ & $0(0.0)$ \\
\hline Vomiting & I $(0.6)$ & I (0.6) \\
\hline
\end{tabular}

$\mathrm{GI}=$ gastrointestinal; $\mathrm{AEs}=$ adverse events

$*_{p}=0.032$ 


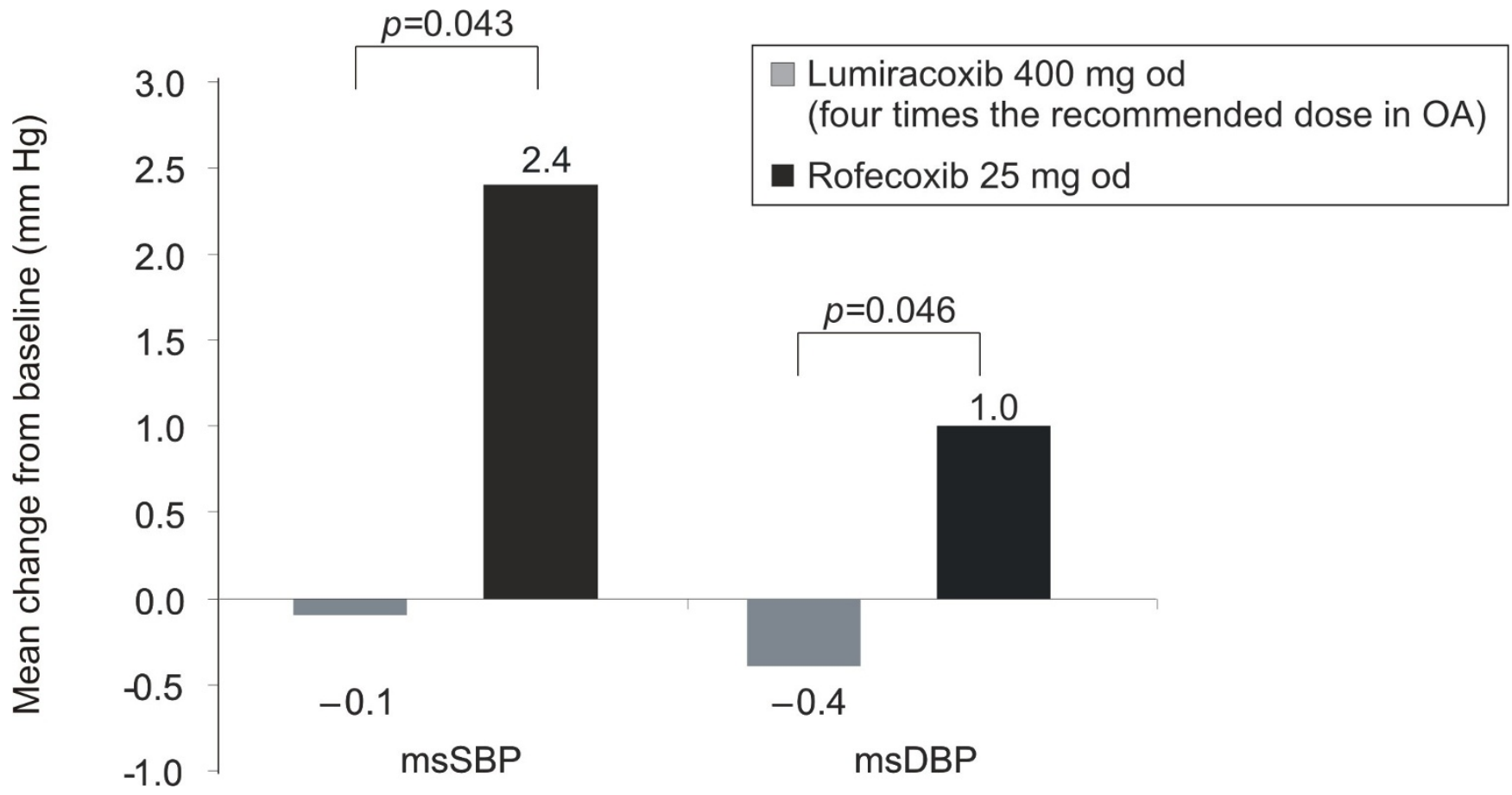

\section{Figure 3}

Lumiracoxib shows better blood pressure profile as compared to rofecoxib (safety population). msSBP - Mean sitting systolic blood pressure. msDBP - Mean sitting diastolic blood pressure. $p$-value computed from ANCOVA on mean blood pressure at Day 42 with centre, treatment, and baseline blood pressure value. Mean change from baseline at Week 6. OA, osteoarthritis.

Serum chemistry and haematology parameters were in the normal range at baseline for the majority of patients in both the treatment groups and remained so at the end of study. No elevations in alanine amino transferase/aspartate amino transferase $>3 \times$ ULN were observed during the study.

\section{Efficacy endpoint}

An improvement in target joint pain or disease activity was reported in $30-40 \%$ of patients in the lumiracoxib and rofecoxib groups after 6 weeks of treatment (Table 5). The differences between the treatment groups were not statistically significant for any efficacy parameter.

Table 3: Incidence of most frequent AEs ( $\geq 2 \%$ for either group) by preferred term (safety population)

\begin{tabular}{|c|c|c|}
\hline & $\begin{array}{c}\text { Lumiracoxib } 400 \mathrm{mg} \text { od } \\
(n=154) \\
n(\%)\end{array}$ & $\begin{array}{c}\text { Rofecoxib } 25 \mathrm{mg} \text { od } \\
(n=155) \\
n(\%)\end{array}$ \\
\hline Dyspepsia & $4 I(26.6)$ & $33(21.3)$ \\
\hline Abdominal pain NOS & $15(9.7)$ & $10(6.5)$ \\
\hline Diarrhoea NOS & $15(9.7)$ & $7(4.5)$ \\
\hline Nausea & $8(5.2)$ & $8(5.2)$ \\
\hline Abdominal pain upper & $4(2.6)$ & $7(4.5)$ \\
\hline Constipation & $4(2.6)$ & I (0.6) \\
\hline Oedema lower limb & $6(3.9)$ & $7(4.5)$ \\
\hline Fatigue & $5(3.2)$ & $4(2.6)$ \\
\hline Nasopharyngitis & $9(5.8)$ & $9(5.8)$ \\
\hline Influenza & $6(3.9)$ & $6(3.9)$ \\
\hline
\end{tabular}

AEs = adverse events; NOS $=$ not otherwise specified 
Table 4: Incidence of deaths and SAEs (Safety population)

\begin{tabular}{|c|c|c|}
\hline & $\begin{array}{l}\text { Lumiracoxib } 400 \mathrm{mg} \text { od } \\
(n=154)\end{array}$ & $\begin{array}{c}\text { Rofecoxib } 25 \mathrm{mg} \text { od } \\
(n=155)\end{array}$ \\
\hline \multicolumn{3}{|l|}{ Patients with serious $A E s$} \\
\hline Death $n(\%)$ & $0(0.0)$ & $0(0.0)$ \\
\hline Non-fatal SAEs $n(\%)$ & $0(0.0)$ & I $(0.6)$ \\
\hline \multicolumn{3}{|l|}{ Patients with other significant AEs } \\
\hline Pre-specified AEs (GI events or oedema) n (\%) & $73(47.4)$ & $64(41.3)$ \\
\hline AEs leading to dose adjustment/interruption $n(\%)$ & $0(0.0)$ & $3(1.9)$ \\
\hline \multicolumn{3}{|l|}{ Discontinuation due to } \\
\hline Any AEs including SAEs $n(\%)$ & $8(5.2)$ & $7(4.5)$ \\
\hline SAEs n (\%) & $0(0.0)$ & $0(0.0)$ \\
\hline AEs (non-serious) $n(\%)$ & $8(5.2)$ & $7(4.5)$ \\
\hline
\end{tabular}

$\mathrm{AEs}=$ adverse events; $\mathrm{SAEs}=$ serious adverse events; $\mathrm{Gl}$ = gastrointestinal

\section{Discussion}

In this study, both lumiracoxib and rofecoxib showed similar efficacy in treating pain associated with OA.

The GI safety profile of lumiracoxib $400 \mathrm{mg}$ od (four times the recommended dose for $\mathrm{OA}$ ) was comparable to rofecoxib $25 \mathrm{mg}$ od over 6 weeks of treatment. The incidence of individual predefined GI AEs and their severity was also comparable between the treatment groups.

Lumiracoxib is indicated at a dose of $100 \mathrm{mg}$ once daily for chronic use in OA, and at doses of $200 \mathrm{mg}$ or $400 \mathrm{mg}$ once daily for short-term use in acute pain indications. While liver toxicity is a known rare but serious side effect of all COX-2 inhibitors and traditional NSAIDs [25], there have been some specific concerns from health authorities regarding the hepatic safety profile of lumiracoxib. Lumiracoxib was withdrawn in Australia in August 2007 following reports of severe liver events occurring predominantly at doses higher than the recommended dose of $100 \mathrm{mg}$ od, when taken chronically. The US FDA issued a non-approvable letter in September 2007, citing concerns over the hepatic profile of lumiracoxib. This was followed by withdrawals in Canada, Europe and a few other countries. Assessment of the benefit to risk profile of the drug is currently ongoing by a number of health authorities.

Liver toxicity is a known rare but serious side effect of all COX-2 inhibitors and traditional NSAIDs and it is not clear the risk is higher with lumiracoxib than other NSAIDs.

In this 6-weeks study no elevations in liver enzymes were observed with lumiracoxib. This is in agreement with the results from TARGET where the incidence of ALT/AST elevations $>3 \times$ ULN were low with lumiracoxib, comparable to ibuprofen and naproxen and no "Hy's cases" (ALT/ AST $>3 \times$ ULN and total bilirubin $>3 \mathrm{mg} / \mathrm{dL}$ ), which are more predictive for severe liver outcome, were observed during the first 49 days of treatment [26].

Traditional NSAIDs and selective COX-2 inhibitors like rofecoxib and etoricoxib have been shown to increase BP

Table 5: Efficacy results in patients treated with lumiracoxib and rofecoxib (ITT population)

\begin{tabular}{|c|c|c|c|c|}
\hline \multirow[b]{2}{*}{ Efficacy measures } & \multicolumn{2}{|c|}{ Week 3} & \multicolumn{2}{|c|}{ Week 6} \\
\hline & $\begin{array}{l}\text { Lumiracoxib } 400 \mathrm{mg} \text { od } \\
\qquad(n=154)\end{array}$ & $\begin{array}{l}\text { Rofecoxib } 25 \mathrm{mg} \text { od } \\
(n=155)\end{array}$ & $\begin{array}{l}\text { Lumiracoxib } 400 \mathrm{mg} \text { od } \\
\qquad(n=154)\end{array}$ & $\begin{array}{l}\text { Rofecoxib } 25 \mathrm{mg} \text { od } \\
(n=155)\end{array}$ \\
\hline \multicolumn{5}{|l|}{ Patient's pain intensity } \\
\hline Improved n (\%) & $53(34.4)$ & $50(32.3)$ & $49(31.8)$ & $63(40.6)$ \\
\hline Non-improved n (\%) & $101(65.6)$ & $105(67.7)$ & $105(68.2)$ & $92(59.4)$ \\
\hline \multicolumn{5}{|c|}{$\begin{array}{l}\text { Patient's global assessment of disease } \\
\text { activity }\end{array}$} \\
\hline Improved n (\%) & $49(31.8)$ & $53(34.2)$ & $57(37.0)$ & 65 (4I.9) \\
\hline Non-improved n (\%) & $105(68.2)$ & $102(65.8)$ & $97(63.0)$ & $90(58.1)$ \\
\hline \multicolumn{5}{|c|}{$\begin{array}{l}\text { Physician's global assessment of } \\
\text { disease activity }\end{array}$} \\
\hline Improved n (\%) & $44(28.6)$ & $46(29.7)$ & $51(33.1)$ & $56(36.1)$ \\
\hline Non-improved n (\%) & $110(71.4)$ & $109(70.3)$ & $103(66.9)$ & $99(63.9)$ \\
\hline
\end{tabular}


in clinical studies $[27,28]$ and in the recent Multinational Etoricoxib and Diclofenac Arthritis Long-Term (MEDAL) study, discontinuations due to hypertension were observed more frequently with etoricoxib compared with diclofenac [29]. In this study, after 6 weeks of treatment, a statistically significantly better BP profile was observed with lumiracoxib as compared to rofecoxib, with an estimated difference of more than $3 \mathrm{mmHg}$ systolic blood pressure (SBP) in favour of lumiracoxib. Although this difference was small, reports suggest that increases in SBP of 1-5 mmHg have been associated with 7100-35 700 additional ischemic heart disease and stroke events in OA patients over a 1-year period in the USA [30]. These findings are consistent with previous findings where a 2 $\mathrm{mmHg}$ decrease in SBP reduced the risk of death due to ischemic heart disease and stroke by approximately $7 \%$ and $10 \%$, respectively, in middle age [31]. Hence, maintaining $\mathrm{BP}$ control can provide substantial benefits in $\mathrm{OA}$ patients [32].

These results are in agreement with the findings of the 12month TARGET outcome study with lumiracoxib, where lumiracoxib had an improved BP profile compared with ibuprofen or naproxen $[22,24]$. The improved BP profile with lumiracoxib as compared to ibuprofen was also observed in hypertensive OA patients [33]. In addition, results from a meta-analysis involving 9611 patients on lumiracoxib (100-400 mg od) revealed that lumiracoxib provided a BP profile (both systolic and diastolic) comparable to placebo [34].

Moreover, in TARGET, the incidence of oedema was low and lumiracoxib was not associated with any increase in the incidence of oedema, compared with ibuprofen or naproxen [35], while in the VIGOR study, the incidence of oedema was higher in the rofecoxib group as compared to the naproxen group [36]. The incidence of peripheral oedema was low and similar in both the groups in this study. A numerical difference for moderate and severe peripheral oedemas was also observed in favour of lumiracoxib, although it did not reach statistical significance.

The incidence of AEs and discontinuations due to AEs were comparable between the treatment groups. The most common AEs suspected by the investigator to be studydrug related were GI AEs, as expected in a study on GI safety.

\section{Conclusion}

Lumiracoxib $400 \mathrm{mg}$ od (four times the recommended dose in OA) demonstrated comparable GI safety profile to rofecoxib $25 \mathrm{mg}$ od (therapeutic dose) in patients with OA. However, lumiracoxib was associated with a significantly better BP profile as compared to rofecoxib.

\section{Abbreviations}

AEs: adverse events; ANCOVA: analysis of covariance; BP: blood pressure; CIs: confidence intervals; COX: cyclooxygenase; CV: cardiovascular; GI: gastrointestinal; ITT: intent-to-treat; LOCF: last-observation-carried-forward; MEDAL: Multinational Etoricoxib and Diclofenac Arthritis Long-Term; msDBP: mean sitting diastolic blood pressure; msSBP: mean sitting systolic blood pressure; NSAIDs: non-steroidal anti-inflammatory drugs; OA: osteoarthritis; Ors: odds ratios; PP: per-protocol; SAEs: serious adverse events; SBP: systolic blood pressure; TARGET: Therapeutic Arthritis Research and Gastrointestinal Event Trial.

\section{Appendix I: List of Investigators}

Austria: Dr. Winfried Graninger, Universitaetsklinik fuer Innere Medizin III, Klin. Abteilung Rheumatologie, Waehringer Guertel 18-20, A-109 Vienna; Dr. Peter Peichl, Kaiser-Franz-Josef-Spital, 2. Medizinische Abteilung mit Rheumatologie und Osteologie der Stadt Wien, Kundratstrasse 3, A-1100 Wien; Dr. Attila Dunky, Wilhelminenspital der Stadt Wien, 5. Mediz. Abteilung $\mathrm{m}$. Rheumatologie, Stoffwechsel, Rehabilitation Montleartstrasse 37, A-11650 Vienna; Dr. Josef Hermann, Medizinische Universitaets Klinik, Universitaet Graz Auenbruggerplatz 15, $8036 \mathrm{Graz}$

Belgium: Prof. P. Geusens, Biomedisch Onderzoeksinstituut - DWI, Limburgs Universitair Centrum, Universitaire Campus - Building C, 3590 Diepenbeek; Prof. Jean-Pierre Devogelaer, Cliniques Universitaire St. Luc, Service de Rhumatologie, Avenue Hippocrate 10, 1200 Bruxelles

France: Dr. C. Copere, Private Practice, Roanne; Dr. A. Duplain, Private Practice, Roanne; Dr. D. Estienne, Private Practice, Roanne; Dr. M. Fleury, Private Practice, Roanne; Dr. P.L. Jacquier, Private Practice, Roanne; Dr. J. Richard, Private Practice, Roanne; Dr. J.M. Aupy, Private Practice, Roanne; Dr. S. Benayoune, Private Practice, Roanne; Dr. J.-M. Blot, Private Practice, Roanne; Dr. D. Brechoire, Private Practice, Roanne; Dr. M. Gacioch, Private Practice, Roanne; Dr. G. Etchegary, Private Practice, Niort; Dr. C. Tilly, Private Practice, Niort; Dr. P. Amlard, Private Practice, Niort; Dr. M. Anthony, Private Practice, Niort; Dr. M. Baert, Private Practice, Niort; Dr. J. Marty, Private Practice, Murs Erigne; Dr. J-F. Pascal, Private Practice, Murs Erigne; Dr. D. Tirouflet, Private Practice, Murs Erigne

Netherlands: Dr. G.J.M. van Doesburg, Private Practice, Lichtenvoorde; Dr. W.A. de Backer, Private Practice, Rijswijk; Dr. C.P. Buiks, Private Practice, Ewijk; Dr. H.F.C.M. Van Mierlo, General Practice Van Mierlo Rembrandt, van Rijn Singel 37-c, 2371 RB Roelofarendsveen; Dr. A. Veerman, Private Practice, Huizen; Dr. M. Passage, Private Practice, Kerkrade 
Switzerland: Dr. med. Hans-Ulrich Rentsch, Rheumatologie, Poststrasse 25, 9000 St Gallen; Dr. R Theiler, Kantonsspital Aarau, Buchserstrasse/Haus 1, 5001 Aarau; Dr. med. Hans Schwarz, Rheumatologie Bethesda-Spital, Gellertstrasse 144, 4020 Basel; Dr. med. Michel Pellaton, 2, ruelle du Peyrou, 2000 Neuchâtel; Dr. Heinz Fahrer, Lindenhofspital/Rheumatologische Klinik, Salihaus Bremgartenstrasse 117, 3012 Bern; Dr. Ottmar Gorschewsky, Klinik Permanence Bern West, Orthopädie Bümplizstrasse 83, 3018 Bern; Dr. Thomas Lehmann, Inselspital/Rheumatologische Klinik Eingang-EG-29/Eingang 14a Freiburgstrasse, 3010 Bern; Dr. Paul Hasler, Felix Platter Spital, Rheumatologie Burgfelderstr. 101, 4012 Basel; Dr. med. Pierre-Alain Buchard, Rhumatologie FMH Clinique romande de réadaptation, Avenue Grand Champsec 90, 1951 Sion; Dr. med. Jean Dudler, Hôspital Nestlé, CHUV Rhumatologie FMH Avenue Pierre-Decker 5, 1005 Lausanne; Dr. Pierre-André Guerne, HCUG Rhumatolgoie, FMH Avenue Beau Séjour 25, 1211 Genève 14; Dr. med. Daniel Uebelhart, Universitätsspital Zürich Gloriastrasse 25, 8091 Zürich; Dr. Urs Moser, Rheumatologie Mühlegasse 3, 4410 Liestal; Dr. med. Michel Braun, Rhumatolgoie FMH Rue Gustave-Amweg 21, 2900 Porrentury

United Kingdom: Dr Alun George, The Staploe Medical Centre, The Staploe Medical Centre Brewhouse Lane Soham, CB7 5JD Cambridge; Dr Duncan Burwood, Bedgrove Surgery, Bedgrove Surgery Brentwood Way, HP2 1 7TL Aylesbury; Dr Andrew Cowie, The Porch Beechfield Road, Corsham, SN13 9 Wiltshire; Dr Robert Matthews, The Spa Surgery, The Spa Surgery 6 Spa Road, SN12 7NS Melksham; Dr Anthony Wright, Hathaway Surgery, Hathaway Surgery 32 New Road, SN15 1 Chippenham; Dr Kevin Gruffydd-Jones, Box Surgery, Box Surgery London Road, SN13 8NA Box, Corsham, Wiltshire

\section{Competing interests}

SY is an employee of Novartis Pharmaceuticals Corporation, East Hanover, NJ. KS and GK are employee of Novartis Pharma AG, Basel, Switzerland (the manufacturer of lumiracoxib). All authors own stocks of the company.

\section{Authors' contributions}

KS and GK participated in analysis and interpretation of the data. Godehard Hoexter performed the original statistical analysis which was then used by SY to conduct the statistical review of this manuscript. All authors contributed to drafting the manuscript. All authors read and approved the final manuscript.

\section{Acknowledgements}

The study and statistical analyses were funded by Novartis Pharma AG. The authors would like to thank the investigators (please see Appendix I for a list of full names), staff of the centres involved in this work, the clinical trial team for their expert collaboration and the patients who participated in the study. The authors would like to thank Godehard Hoexter, the clinical trial statistician and Elena Ehrsam the clinical trial leader for their expert contribution to the study and data analysis. In addition the authors would like to thank the medical writers Lakshmi Venkatraman and Vikrant Pallapotu (DOC-India, Novartis) for their assistance with drafting the manuscript and incorporating subsequent revisions.

\section{References}

I. Woolf $A D$, Pfleger B: Burden of major musculoskeletal conditions. Bull World Health Organ 2003, 8 I (9):646-656.

2. Recommendations for the medical management of osteoarthritis of the hip and knee: 2000 update. American College of Rheumatology Subcommittee on Osteoarthritis Guidelines. Arthritis Rheum 2000, 43(9): 1905-1915.

3. Laine L: Approaches to nonsteroidal anti-inflammatory drug use in the high-risk patient. Gastroenterology 2001, I 20(3):594-606.

4. Wolfe MM: NSAIDs and the gastrointestinal mucosa. Hosp Pract (Minneap) 1996, 3 I ( I 2):37-44.

5. Talley N, Evans J, Fleming K, Harmsen W, Zinmeister A, Melton L III: Nonsteroidal anti-inflammatory drugs and dyspepsia in the elderly. Dig Dis Sci 1995, 40:1345-1350.

6. Laine $L:$ The gastrointestinal effects of nonselective NSAIDs and COX-2-selective inhibitors. Semin Arthritis Rheum 2002, 32(3 Suppl I):25-32.

7. Singh G, Ramey DR, Morfeld D, Shi H, Hatoum HT, Fries JF: Gastrointestinal tract complications of nonsteroidal anti-inflammatory drug treatment in rheumatoid arthritis. A prospective observational cohort study. Arch Intern Med 1996, 156(14): 1530-1536.

8. Singh G, Triadafilopoulos G: Epidemiology of NSAID induced gastrointestinal complications. J Rheumatol Suppl 1999, 56:18-24.

9. Goldstein JL, Correa P, Zhao WW, Burr AM, Hubbard RC, Verburg KM, Geis GS: Reduced incidence of gastroduodenal ulcers with celecoxib, a novel cyclooxygenase-2 inhibitor, compared to naproxen in patients with arthritis. Am J Gastroenterol 200I, 96(4): 1019-1027.

10. Langman MJ, Jensen DM, Watson DJ, Harper SE, Zhao PL, Quan H, Bolognese JA, Simon TJ: Adverse upper gastrointestinal effects of rofecoxib compared with NSAIDs. Jama 1999, 282(20): 1929-1933.

II. Merck \& Company, Inc. Merck announces voluntary worldwide withdrawal of VIOXX [http://www.vioxx.com/vioxx/docu ments/english/vioxx press release.pdf]

12. FDA: [http:/www.fda.gov/bbs/topics/news/2005/NEW0I/7/.html].

13. Kearney PM, Baigent C, Godwin J, Halls H, Emberson JR, Patrono C: Do selective cyclo-oxygenase-2 inhibitors and traditional non-steroidal anti-inflammatory drugs increase the risk of atherothrombosis? Meta-analysis of randomised trials. $\mathrm{Bmj}$ 2006, 332(7553): 1302-1308.

14. Singh G, Wu O, Langhorne P, Madhok R: Risk of acute myocardial infarction with nonselective non-steroidal anti-inflammatory drugs: a meta-analysis. Arthritis Res Ther 2006, 8(5):RI53.

15. Zelenakas K, Fricke JR Jr, Jayawardene S, Kellstein D: Analgesic efficacy of single oral doses of lumiracoxib and ibuprofen in patients with postoperative dental pain. Int J Clin Pract 2004, 58(3):25I-256.

16. Willburger RE, Mysler E, Derbot J, Jung T, Thurston HJ, Kreiss A, Litschig S, Krammer G, Tate GA: Lumiracoxib 400 mg once daily is comparable to indomethacin $\mathbf{5 0} \mathbf{~ m g}$ three times daily for the treatment of acute flares of gout. Rheumatology (Oxford) 2007, 46(7): I I26-II 32.

17. Chan VW, Clark AJ, Davis JC, Wolf RS, Kellstein D, Jayawardene S: The post-operative analgesic efficacy and tolerability of lumiracoxib compared with placebo and naproxen after total knee or hip arthroplasty. Acta Anaesthesiol Scand 2005, 49(10): $|49|-\mid 500$.

18. Kyle C, Zachariah J, Kasangra M, Andrews C, Ellis G, Kinch H: Lumiracoxib $\mathbf{4 0 0} \mathbf{~ m g}$ once daily is comparable to naproxen $\mathbf{5 0 0}$ mg twice daily for treatment of acute muscular pain following soft tissue injury [abstract]. Ann Rheum Dis 2006, 65:24I. 
19. Pavelka K, Zamani O, Alten R, Yu S, Litschig S, Sloan VS: Lumiracoxib is effective and well tolerated in the long-term treatment of knee osteoarthritis. Ann Rheum Dis 2005, 64:353.

20. Fleischmann R, Tannenbaum H, Patel NP, Notter M, Sallstig P, Reginster J-Y: Retention on treatment with lumiracoxib in patients with osteoarthritis [abstract]. Osteoarthritis Cartilage 2006, I 4:SI65.

21. Schnitzer TJ, Burmester GR, Mysler E, Hochberg MC, Doherty M, Ehrsam E, Gitton X, Krammer G, Mellein B, Matchaba P, et al.: Comparison of lumiracoxib with naproxen and ibuprofen in the Therapeutic Arthritis Research and Gastrointestinal Event Trial (TARGET), reduction in ulcer complications: randomised controlled trial. Lancet 2004, 364(9435):665-674.

22. Farkouh ME, Kirshner H, Harrington RA, Ruland S, Verheugt FW, Schnitzer T], Burmester GR, Mysler E, Hochberg MC, Doherty M, et al.: Comparison of lumiracoxib with naproxen and ibuprofen in the Therapeutic Arthritis Research and Gastrointestinal Event Trial (TARGET), cardiovascular outcomes: randomised controlled trial. Lancet 2004, 364(9435):675-684.

23. Hawkey CJ, Weinstein W, Smalley WE, Richard D, Krammer G, Sallstig $P$, Mellein B, Matchaba P: Significant early reduction of ulcer complications with lumiracoxib compared with naproxen at Day 8 of treatment in TARGET. In DDW Washington DC; 2007.

24. Farkouh ME, Verheugt FWK, Kirshner H, Ruland S, Sallstig P, Stricker K, Krammer G, Mellein B, Gitton X, Matchaba P, et al.: Lumiracoxib provides superior blood pressure profile compared to NSAIDs after 4 weeks of treatment. Poster No I692, ACR/ARHP 2006 Annual Scientific Meeting, Washington .

25. Traversa G, Bianchi C, Da Cas R, Abraha I, Menniti-Ippolito F, Venegoni $M$ : Cohort study of hepatotoxicity associated with nimesulide and other non-steroidal anti-inflammatory drugs. $B M J$ 2003, 327:18-22.

26. Hawkey C], Weinstein WM, Stricker K, Murphy V, Richard D, Krammer G, Rebuli R: Comparison of the gastrointestinal safety of lumiracoxib with traditional NSAIDs early after the initiation of treatment: findings from the Therapeutic Arthritis Research and Gastrointestinal Event Trial (TARGET). Aliment Pharmacol Ther 2008, 27:838-845.

27. Johnson AG, Nguyen TV, Day RO: Do nonsteroidal anti-inflammatory drugs affect blood pressure? A meta-analysis. Ann Intern Med 1994, I 2 I (4):289-300.

28. Aw TJ, Haas SJ, Liew D, Krum H: Meta-analysis of cyclooxygenase-2 inhibitors and their effects on blood pressure. Arch Intern Med 2005, I 65(5):490-496.

29. Cannon CP, Curtis SP, FitzGerald GA, Krum H, Kaur A, Bolognese JA, Reicin AS, Bombardier C, Weinblatt ME, Heijde D van der, et al: Cardiovascular outcomes with etoricoxib and diclofenac in patients with osteoarthritis and rheumatoid arthritis in the Multinational Etoricoxib and Diclofenac Arthritis Long-term (MEDAL) programme: a randomised comparison. Lancet 2006, 368(9549): $|77|-|78|$.

30. Singh G, Miller JD, Huse DM, Pettitt D, D'Agostino RB, Russell MW: Consequences of increased systolic blood pressure in patients with osteoarthritis and rheumatoid arthritis. J Rheumatol 2003, 30(4):7|4-7I9.

31. Lewington S, Clarke R, Qizilbash N, Peto R, Collins R: Age-specific relevance of usual blood pressure to vascular mortality: a meta-analysis of individual data for one million adults in 61 prospective studies. Lancet 2002, 360(9349): |903-1913.

32. Grover SA, Coupal L, Zowall H: Treating osteoarthritis with cyclooxygenase-2-specific inhibitors: what are the benefits of avoiding blood pressure destabilization? Hypertension 2005, 45(I):92-97.

33. MacDonald TM, Richard D, Lheritier T, Krammer G: Improved blood pressure control in hypertensive patients with osteoarthritis treated with lumiracoxib: randomized controlled trial of lumiracoxib versus ibuprofen [abstract]. J Clin Hypertens 2007, 9:A91-A92

34. Whitehead A, Simmonds M, Mellein B, Friede T, Gitton X, Sallstig P: Blood pressure profile of lumiracoxib is similar to placebo in arthritis patients. Osteoarthritis Cartilage 2006, I4:SI68-SI69.

35. Zacher J, Hasler P, Martín Mola E, Mellein B, Krammer G, Gitton X: Therapeutic Arthritis Research and Gastrointestinal Event Trial (TARGET) of lumiracoxib versus NSAIDs: incidence of de-novo hypertension and oedema. Ann Rheum Dis 2005, 64:483.
36. FDA: : I0 [http://www.fda.gov/ohrms/dockets/ac/0I/briefing/3677b2 06 cardio.pdf].

\section{Pre-publication history}

The pre-publication history for this paper can be accessed here:

\section{http://www.biomedcentral.com/1471-2474/9/118/pre} pub
Publish with Bio Med Central and every scientist can read your work free of charge

"BioMed Central will be the most significant development for disseminating the results of biomedical research in our lifetime. "

Sir Paul Nurse, Cancer Research UK

Your research papers will be:

- available free of charge to the entire biomedical community

- peer reviewed and published immediately upon acceptance

- cited in PubMed and archived on PubMed Central

- yours - you keep the copyright
BioMedcentral 